Archived version from NCDOCKS Institutional Repository http://libres.uncg.edu/ir/asu/

\title{
Appalachľan
}

B O O N E, N O R T H C A R O L I N A

\section{Metajournalistic Discourse On The Rise Of Gaming Journalism}

\author{
By: Gregory Perreault and Tim Vos
}

\begin{abstract}
Gaming journalism, which finds its origins in public relations-oriented gaming magazines, discursively attached itself to traditional journalism in the wake of the 2014 GamerGate controversy. Yet it had remained unclear where gaming journalism fits within the ecology of journalism. This study examines metajournalistic discourse regarding gaming journalism from 2010 to 2018 and analyzes 53 articles about gaming journalism from that period in order to understand how the broader journalistic field conceptualized gaming journalism's place within it. This study argues that gaming journalism is discursively marked as a lower, marginal form of journalism based on perceived differences in professional values and journalistic savviness.
\end{abstract}

Perreault G, Vos T. Metajournalistic discourse on the rise of gaming journalism. New Media \& Society. 2020;22(1):159-176. doi:10.1177/1461444819858695. Publisher version of record available at: https://journals.sagepub.com/doi/full/10.1177/1461444819858695 


\title{
Metajournalistic discourse on the rise of gaming journalism
}

\author{
Gregory Perreault \\ Appalachian State University, USA
}

\section{Tim Vos}

Michigan State University, USA

\begin{abstract}
Gaming journalism, which finds its origins in public relations-oriented gaming magazines, discursively attached itself to traditional journalism in the wake of the 2014 GamerGate controversy. Yet it had remained unclear where gaming journalism fits within the ecology of journalism. This study examines metajournalistic discourse regarding gaming journalism from 2010 to 2018 and analyzes 53 articles about gaming journalism from that period in order to understand how the broader journalistic field conceptualized gaming journalism's place within it. This study argues that gaming journalism is discursively marked as a lower, marginal form of journalism based on perceived differences in professional values and journalistic savviness.
\end{abstract}

\section{Keywords}

Gaming journalism, journalistic ecology, lifestyle journalism, metajournalistic discourse, qualitative methods

\section{Introduction}

Little is known about how gaming journalism, which originated out of public relationsoriented gaming magazines and enthusiast press publications, fits into the contemporary ecology of journalism. In the wake of controversy surrounding so-called GamerGate,

\footnotetext{
Corresponding author:

Gregory Perreault, Department of Communication, Appalachian State University, Boone, NC 28607, USA.

Email: perreaultgp@appstate.edu
} 
gaming journalists discursively positioned their work as little different from traditional journalism (Perreault and Vos, 2018). It is not altogether clear whether journalists working in legacy outlets have welcomed gaming journalists into the professional fold. New entrants to the journalistic field are not necessarily welcomed, in fact the field can prove "resistant to disruptions" (Vos et al., 2012: 9). Understanding how journalists discursively position new entrants - either to welcome or deny entry-helps provide a sense of how journalists view changes in their field and the field more broadly (Carlson and Lewis, 2015). In other words, how journalists discuss gaming journalism provides a sense of journalists' own paradigmatic values.

Discussion among journalists regarding journalism — referred to as metajournalistic discourse - is the means through which "meanings of journalism are formed and transformed by actors inside and outside of journalism" (Carlson, 2015: 350). By extension, this is how the journalistic field defines the boundaries of appropriate and inappropriate news practice (Winch, 1997), and repairs its paradigm in the face of criticism (Carlson, 2009; Hindman, 2005). This study seeks to examine metajournalistic discourse regarding gaming journalism and its attempt to situate itself firmly in the journalistic field. Drawing on a collection of metajournalistic discourse from two dozen sites over multiple years, this research analyzes the discursive strategies employed by traditional journalists to establish the relative legitimacy of gaming journalism in the field.

Lifestyle journalism, of which gaming journalism is but one part, has often been seen as less important than journalism related to politics, economics, and other so-called hard news genres (Hanusch, 2012). In the overall ecology of journalism, some forms of journalism hold more normative weight than other forms. While political and other hard news topics resonate with paradigmatic values of objectivity, public service, and watchdog journalism, lifestyle journalism has been associated with values of subjectivity, market-driven motives, and celebratory journalism (Hanitzsch, 2007; Hanusch, 2012). However, the events surrounding GamerGate highlighted that gaming journalism covers important public issues, such as sexism and online harassment (Perreault and Vos, 2018), and hence invited a reconsideration of the tidy divide between traditional journalism and lifestyle journalism. Thus, the value of this study is in better understanding how metajournalistic discourse functions to map journalism's normative and practical ecology.

\section{Metajournalistic discourse}

Studies of metajournalistic discourse inquire how "utterances about journalism shape news practices" and connect the "creation and circulation of journalism's sociocultural meanings to the social practices surrounding news production and consumption" (Carlson, 2015: 350). The discourse serves the "double-duty" of providing meaning for the journalistic community and defining journalism to the public (Berkowitz, 2000). Through the frameworks of interpretive community, paradigm repair, boundary work and collective memory, journalists can be seen as protecting their paradigm and working to control the boundaries of the field. Metajournalistic discourse speaks of whether particular actors have a place within the broader journalistic ecology and locates that 
place. In metajournalistic discourse, journalists can be "dismissed by the objects of their critique (other journalists)" or conversely, they can be "regarded positively, as independent from and not beholden to the larger forces and structures of the journalistic field" (Eldridge, 2019: 7). Journalists mark off boundaries of appropriate and inappropriate journalistic practice. These discursive constructions affect the distribution of resources and epistemic authority - the degree to which the journalistic knowledge process is seen as legitimate.

New forms of media tend to be embraced by the field if they value the field's existing aspirations and understandings (Carlson and Usher, 2016; Perreault and Stanfield, 2019). When confronted by changes in the journalistic field, it is natural for journalists to look to the "stability of the past" in defining their work (Carlson, 2014: 44). In particular, journalists tend to identify misperforming journalists as "scapegoats" to be kept in "perpetuity" in order to bear the brunt of criticism for inappropriate practices (Carlson, 2014: 45), a process journalists worked through in the midst of the 2014 GamerGate controversy. The controversy saw gaming journalists accused of a too-close relationship with the gaming industry (Perreault and Vos, 2018) - an issue that would have implications for the subfield's location within the broader journalistic ecology. The controversy emerged amidst allegations that a game developer had slept with a prominent gaming journalist in order to obtain better coverage for her game. While the allegations were quickly disproved, what followed was a sustained campaign of harassment against women involved in game development, gaming criticism, and gaming journalism. Simultaneously, GamerGate raised questions about "ethics in gaming journalism" (Massanari, 2017: 334). While some GamerGate proponents seemed sincerely motivated by concerns regarding collusion between gaming journalists and the gaming industry, research also suggests that GamerGate proponents were largely motivated by desires to exclude female gamers from the gaming culture (Foxman and Nieborg, 2016).

Understanding how the journalistic field responded to attempts by gaming journalists to claim membership in the field could shed light not just on how traditional journalism discourses situate a form of lifestyle journalism, but also elucidate paradigmatic values central to journalism - values that are often not articulated until there is controversy (Berkowitz, 2000).

\section{Covering gaming}

As with other media technologies, video games were initially vilified in news coverage before eventually being redeemed (Williams, 2003). A content analysis of reception and presentation of video games in leading US magazines over a 30-year period showed that journalists presented video games in both utopian and dystopian frames. Video games could "transcend nature, add convenience to daily life, and spread egalitarian, democratic values" but also be "morally bankrupt, poisonous to participation in democratic society, and to have created new stresses and inequalities" (Williams, 2003: 525). Williams (2003) argued that the positive portrayal could partly be a result of the journalistic norm of balanced reporting. Williams (2003) noted that negative coverage often occurred in response to political rhetoric. For example, in the 1980s, the "conservative establishment already struggling with a rapidly changing and increasingly diverse 
society" used gaming as a way to identify deviance (Williams, 2003: 544). Gaming has existed as a paradoxical activity. As a form of art, gaming provides a chance for players to consider the world differently and provides "an opening onto different ways of living" (Kirkpatrick, 2013: 12). In Kirkpatrick's (2013) conception of the gaming imaginary, he argues that at once gaming is "pleasurable, harmless, and fun," and yet critiqued over concerns about "addiction, aggression and that play is a wasteful activity" (Kirkpatrick, 2013: 7) - a conception developed at least in part through the mediation of gaming by journalists (Williams, 2003). This imaginary exists as a sort of collective memory bridging abstract ideas about the social world and our empirical experience of the world (Sparre and From, 2017).

As a type of lifestyle journalism concerned with arts and culture, gaming coverage provides "symbolic value to art forms and cultural objects" (Heikkilä et al., 2018: 5). As such, news coverage of games is a kind of taste-making. Gaming journalists play a role in "disseminating and legitimizing cultural products and evaluating what can be considered 'good taste' (p. 5). In research on the culture of arts journalists, Harries and WahlJorgensen (2007) indicated why journalists reporting on a cultural artifact could consider themselves journalists, but yet 'exceptional within the culture of journalism' (p. 635). Indeed, arts criticism has sat uncomfortably within journalism: (1) arts journalists are journalists but need specialist knowledge in order to communicate to the public the complicated nature of artifacts, (2) arts coverage does not fit easily into 'hard news' categories, yet arts journalists would describe their work as more important than traditional news, and (3) arts journalists subscribe to notions of objectivity, although objectivity has 'less relevance' in this form of journalism (Harries and Wahl-Jorgensen, 2007: 635), since subjectivity is largely inseparable from arts reporting (Chong, 2019). But whereas arts journalists ultimately claim that art improves society (Harries and WahlJorgensen, 2007), gaming journalists do not make such claims about games (Foxman and Nieborg, 2016). Nevertheless, gaming journalists are like arts journalists in that they see themselves as intermediaries between cultural producers and the public (Riegert et al., 2015: 774). The close relationship between cultural journalists and culture industries requires journalists to perform 'complex and intertwined roles as cultural gatekeepers, connectors, marketers and valorisers, roles that are quite different from, for example, the norms and roles of autonomous, objective disseminators, watchdogs or observers, typically associated with Western journalism' (Kristensen, 2018: 2182). Kristensen (2018) notes that cultural journalists such as gaming journalists must practice a form of 'churnalism': recycling information from press releases with little attempt at verification or independent reporting. It then follows that cultural journalists would, in contrast to traditional journalists, hold 'different conceptions of their societal obligations and professional values' that are informed by their journalistic paradigm (Kristensen, 2018: 2171).

\section{Gaming journalism}

Among journalists who write about gaming, the use of the word journalism has been uncomfortable when applied to the gaming press (Nieborg and Sihvonen, 2009). As with other forms of cultural journalism- "the decision to label oneself either as a critic or 
journalist has less to do with their occupational ethos or practices than with the institutional affiliation of authors" (Foxman and Nieborg, 2016: 4).

Gaming journalism in the United States is often considered to have originated in 1981 with Electronic Games Magazine, published by Bill Kunkel and Arnie Katz- the first enthusiast news publication that only featured video games (Johnson, 2010). The same year, Computer Gaming World launched with news about computer gaming. Through the 1980 s, a number of news organizations began covering the phenomenon-notably popular publications such as GamePro Magazine and Nintendo Power. The 1990s witnessed substantial changes in the industry with the arrival of the Internet and the emergence of new publications with corporate attachments: during this time Computer Gaming World was purchased by Microsoft, transforming into Games for Windows: The Official Magazine, and EB Games debuted the magazine Game Informer (Johnson, 2010; Kain, 2014). In 2004, gaming critic Kieron Gillen published an essay "The New Games Journalism," arguing that gaming journalism had to move past looking at the game solely in terms of internal criteria - design, graphics, plot - and instead consider that the value of gaming was in the player experience (Jeffries, 2009). And while the piece was controversial in gaming circles, it was nevertheless followed by more thoughtful, playerfocused reporting in magazines such as PC Gamer, and websites such as Polygon and Kotaku (Jeffries, 2009).

Much of early gaming journalism operated as a buyer's guide - providing advice (through its criticism) about what to purchase. This advice-oriented criticism aligned with a shift in journalism toward soft news (Hanusch, 2012). Soft news is typically described as more opinion-oriented, advice-driven, and entertaining (Coward, 2013). Hanusch (2012) describes this type of journalism as lifestyle journalism. It is a marketdriven form of journalism in which Hanitzsch (2007) argues, "the materialization of ... lifestyle journalism exemplifies [the] trend toward a blending of information with advice and guidance" (p. 375). Lifestyle journalism often functions by offering "judgments of taste" and serves as a venue of relevant cultural negotiations (Fürsich, 2012: 13). Broadly, this form of journalism exists on a continuum, stretching from market-driven guidance to critical reflection (From, 2010) and blurs the line between public relations and journalism (Gwaltney, 2014). Consequently, the audience views the journalism as a commercial product of the news institution (From, 2010).

Gaming journalism's own history has made it unique. Foxman and Nieborg (2016) note that gaming journalists "have always been in direct contact with their readers, arguably more so than mainstream critics" (p. 10), and hence the field is entrenched within games culture and "bound with the identity of a gamer" (p. 4). Yet this identity was developed through exclusionary practices in gaming journalism and amidst an uncomfortable relationship with the gaming industry. The journalists' fear of alienating the industry they depend on has led to a "pervasive sense of resignation among journalists and is used to justify self-censorship and self-imposed limits" (Foxman and Nieborg, 2016: 19). Gaming journalism is unique in its own constitutive ambivalences - "inherent contradictions shared by gamers and game criticism that have shaped and still shape the cultural perception and position of their beloved medium" (Foxman and Nieborg, 2016: 7). During the 2014 GamerGate controversy, gaming journalists wanted to "link their work with the roles, ethical procedures and professional practices of traditional journalists" (Perreault 
and Vos, 2018: 565) as a way to position their work within the mainstream of the journalism ecology and to therefore blunt criticisms.

\section{Journalism ecology}

"Journalism ecology" has been used loosely to refer to the overall array of types of journalism, each type contributing something to the overall media environment (Dovey, 2008; Scolari, 2012; Tracy, 2012). Similar discourse refers to the news market (Mullainathan and Shleifer, 2005) or journalism marketplace (Pavlik, 2013) to convey differentiation within journalism. However, this limits the logic of differentiation to market motives and fails to convey the normative logic that sometimes drives differentiation within metajournalistic discourse.

Much of the focus has been on different technological platforms or media for delivering news (Scolari, 2012) — each bringing different affordances and foci to journalism. But the journalism ecology can certainly involve other distinctions (Allan and Thorsen, 2009): differentiation by geographic orientation (e.g. hyper-local, local, national), audience-orientation (e.g. young, old, LGBTQ), content or topic orientation (e.g. business, sports, technology), style orientation (e.g. long-form narrative, breaking news) and orientation by voice (e.g. detached-objective, indignant, snarky). It can also involve political orientation (e.g. liberal, conservative or neutral, advocacy journalism) or even journalists' employment status (e.g. professional, citizen journalism). The idea is that "a range of ... outlets together form the diverse totality of contemporary news production" (Bruns et al., 2009: 204) as well as news consumption (Flaxman et al., 2016).

While the metaphor suggests that the "species" of journalism have a place in the ecosystem and that they are reliant on each other to some degree (Scolari, 2012: 209), hierarchies can and do exist. Print journalists, for example, traditionally looked down on broadcast journalists, disparaging broadcast news as shallow or corrupted by entertainment values (Newman and Levine, 2012). Of course, these hierarchies are not fixed, and hence metajournalistic discourse offers ongoing attempts to assert professional and moral hierarchies among the species of journalism (Carlson and Lewis, 2015). These can sometimes manifest as contests of legitimacy - discursive battles over what is deemed proper journalism. In other words, the discourse exposes the principles or norms of the journalistic paradigm (Berkowitz, 2000).

Through the lens of journalism ecology, lifestyle journalists could be regarded as a different species of journalist, relegated to the margins of traditional journalism (Carlson, 2015; Carlson and Lewis, 2015). This study then conceptualizes the "traditional journalist" as the hard news journalist, whose role is typically articulated in relation to watchdog roles and/or the concept of objectivity; who exists in a dominant place with the journalistic ecology (Hanitzsch, 2007; Hanusch, 2012). ${ }^{1}$

Thus, we arrive at a set of research questions that guide our inquiry:

RQ 1: How does metajournalistic discourse construct the relative legitimacy of (a) gaming as a news subject and (b) gaming journalism as journalism practice? 
RQ 2: How does the metajournalistic discourse about gaming journalism engage paradigmatic values of traditional journalism?

RQ 3: How does the metajournalistic discourse about gaming journalism place gaming journalism within the broader ecology of journalism?

\section{Study design}

It stands to reason that this study relies on discourse analysis to examine metajournalistic discourse. Discourse is "language in use" and emerges from "a process which is socially situated" (Candlin, 2014: ix). Discourse analysis, then, seeks to understand language in the institutional and social contexts in which it is located. Analysis is directed at the ways language use constructs meaning, paying particular attention to how word choices, rhetorical strategies, and argumentation are used to legitimize and delegitimize actions or actors (Hall, 1980; Van Dijk, 1980). The focus is typically on "actual patterns of use in naturally occurring texts" (Alba-Juez, 2009: 18).

Gaming journalists described significant development in their field in the years before GamerGate in 2014 (Perreault and Vos, 2018). As such, researchers collected data from 1 January 2010 to 1 January 2018 to bookend the GamerGate controversy on both sides and to try to highlight metajournalistic discourse regarding gaming journalism both before and after gaming journalists linked "themselves with established journalistic entities and practices" (p. 565). This also comports with Carvalho's (2008) call to attend to the temporal arcs of discourse. Data were collected using the databases ProQuest, LexisNexus, and the Discourses of Journalism project, a metajournalistic discourse database through the Missouri School of Journalism, which drew content from 22 sites of metajournalism. Researchers searched for English news articles from traditional newspapers, magazines, and websites/blogs. This focus presumes traditional journalists will likely view the journalism ecology based on their assumed place atop a journalism hierarchy, although that remains an empirical question.

Given that gaming journalism, like much lifestyle journalism, falls on the line between designations of news and criticism (Perreault and Vos, 2018), search terms included both "journalism" and "criticism" as designators. This resulted in the search terms "video game journalism," "gaming journalism," "video game criticism," and "gaming criticism." This initially created a large population-656 in ProQuest, 415 in LexisNexus, and 87 through the [redacted] database - that was paired down for relevance to the topic and duplicate articles were removed. The final data analysis examined 53 discrete objects of metajournalistic discourse about gaming journalism, mostly from US outlets. Some of the writers turned out to have written for gaming publications, which is a potential limitation. Nevertheless, it also seems plausible that journalists' institutional location in traditional outlets would inform their (new) identity and judgments (see Ferrucci and Vos, 2017). Inclusion criteria required that the article featured journalists addressing gaming journalism. Articles were excluded if they (1) referenced only gaming with no regard to the mediatization of gaming, or (2) served as a piece of actual gaming criticism with no broader context of the journalistic ecology. The discrete objects of analysis were journalistic discourses. 
The authors analyzed the data using a constant comparative approach to arrive at themes that addressed the research questions (Glaser and Strauss, 1968). While the constant comparative method is often associated with grounded theory, Fram (2013) argues that constant comparative analysis is well suited to both etic coding, driven by theory and literature, and emic coding, driven by themes that emerge from data analysis. Analysis had the goal of identifying possible socially constructed meanings (Coffey and Atkinson, 1996). In this study, following the model of Leech and Onwuegbuzie (2008) for constant comparative research and Emerson et al. (2011) for qualitative data analysis, the authors individually read all data, and took notes that were then discussed as a research team. Then the researchers returned to the data to identify discursive themes. Finally, the authors once again approached data and took detailed notes, and drew out quotes deemed to best represent the discursive themes that emerged (Emerson et al., 2011; Leech and Onwuegbuzie, 2008).

\section{Findings}

\section{Constructing legitimacy}

RQ1 asked: How does metajournalistic discourse construct the relative legitimacy of (a) gaming as a news subject and (b) gaming journalism as journalism practice?

The metajournalistic discourse indicated that gaming was a relevant news topic based on the gaming industry's economic impact, the artistic content, gender issues, and continued debates about games and violence. Video games are, after all, a "\$100 billion a-year industry, bigger than Hollywood box-office and the global music industry put together" (Stuart, 2017); and an industry that has "grown so huge that it is now mainstream" (Shenzhen Daily, 2014). Stuart (2017) makes the case that the commercial success is illustrative of the medium's development-games are so big, he argues, that gaming journalists should think of themselves more like travel journalists (interestingly, another form of lifestyle journalism). In addition, commercial success illustrates the changing culture of gaming among game players, game developers, and gaming journalists (Stuart, 2017).

Journalists' discourse also deemed video games to be an "art form" facing the "same hurdles as comics and graphic novels" (Wos, 2014) and noted that even the Museum of Modern Art recognizes "video games as an important part of our culture's creative output" (Trueman, 2013) and, hence, the "cultured person ought to have an informed opinion" (Suellentrop, 2014). In some cases, journalists noted that more cerebral games, such as Depression Quest, were often so artistic that they were attacked for not being a game (Prebble, 2014).

Yet, journalistic discourse also noted that the games industry has well-publicized difficulties in representations of women and inclusion of women in game development. Sauter (2016) noted that women need more attention in gaming culture, since they have been "producing and designing important, fascinating games for years now." That said, "women have been knocking at [the door] since the inception of video games in the early 1970s, but like most 'boys clubs,' the admission of women has been met with resistance and resentment" (Wos, 2014). And there were issues that journalists deemed worthy of 
critique in that many games use women as "background decoration" or as a "way for the male protagonist to establish themselves" (Wos, 2014).

Finally, the discourse continually returned to gaming as a factor in the cyclical coverage of mass shootings. One noted that "rightly or wrongly, video games have been blamed for fostering a violent culture that appeals to troubled individuals" (Tsukayama, 2014) and that some games include plenty of violent imagery, such as Grand Theft Auto's plot lines that involve "stealing cars, shooting men and 'accidentally' running over pedestrians" (Clarke, 2014). This discourse was largely a response to the US National Rifle Association (NRA), which often shifted blame after school shootings to the video game industry. The discourse questioned the continued adherence to this narrative. As one report noted, in the weeks after the Newtown school shooting that left 27 children dead, the NRA introduced its own "gun-themed shooting game" (Ingle, 2013). In short, the "NRA doesn't even take its own claims seriously" (Ingle, 2013). This discourse falls in line with prior research by Williams, (2003), which found gaming was framed in negative ways, particularly when political rhetoric used gaming as a scapegoat, a tactic predominantly adopted by conservative groups to generate fear (Williams, 2003).

The discourse indicates the degree to which journalists found subjects surrounding the topic of gaming to be newsworthy. Like any worthwhile news topic, video games fell within the largely taken for granted assumptions of newsworthiness. Gaming involved a worthy cultural and social matter, touching on economic and political issues frequently at the center of so-called hard news.

That being said, journalists largely deemed the current quality of gaming journalism to be poor. For example, upon the death of Bill Kunkel, who was lauded by journalists as "an inventor of video game journalism" (Slotnik, 2011), his excellent writing was described as the exception, as opposed to the rule. "Mr. Kunkel's writing on the subject, however, characterized by a literacy lacking in most video game coverage, survived decades longer in other publications and online" (Slotnik, 2011). Part of what made his gaming journalism strong, the author implied, is that he was willing to critique problems in the industry, such as a "focus on processing power," low "creativity," an emphasis on sequels, and an overall sense that the "canvas keeps getting bigger and the ideas are getting smaller" (Slotnik, 2011). In short, his willingness to critique gaming meant it was hard to see Kunkel's work as simply a commercial product (see Fürsich, 2012), largely because it added "symbolic value" to the games he discussed (see Heikkilä et al., 2018: 5).

Conversely, in a review of a book written by a gaming journalist (Sauter, 2016), the book "trips over many of the same stumbling blocks that hamper most video game writing today." The piece argues that the book from a renowned gaming journalist - Simon Parkin - misses opportunities to engage with contemporary "game studies or technology criticism"- which could have been used to great effect to bolster his arguments (Sauter, 2016). The journalist also argued that the gaming journalist's arguments "lack the gravity to answer the deep questions he poses," a result - it is implied - of not interrogating the broader context in which games are discussed. The criticism perhaps indicates a lack of specialist knowledge on Parkin's part, or at the very least the piece argues that he failed to deploy that specialist knowledge (see Harries and Wahl-Jorgensen, 2007). Other discourse noted that gaming journalists could learn from other entertainment writing beats-gaming journalists need to learn to "analyze and interpret the 
industry," "provide context and draw interesting conclusions," "add depth and soul to the experience of learning new things" (Stuart, 2017), and "tell a story, not just give a thumbs up or thumbs down" (Ellis, 2012). A journalist argued that gaming journalism "misses opportunities" to add diversity to sourcing" (Sauter, 2016), and provide a "holistic approach" in their coverage, (Ellis, 2012). These critiques showcase a concern over the scope of gaming culture being provided by gaming journalists, a scope that would be naturally expected if gaming journalists were acting as actual cultural intermediaries (see Riegert et al., 2015).

The visibility of the GamerGate controversy correlated with a marked increase in both reporting about gaming and discussion of gaming journalism. Yet, this attention came at a cost. Much of the coverage prior to GamerGate largely reflected Williams' (2003) utopian framing: gaming was largely covered in relation to technological development, for example, through an emphasis on changing patterns in gaming reporting away from "computer magazines" (May 2013, 18 June) and toward digital journalism in a more "grassroots 'everyman' approach" (Hum, 2013). In the midst of GamerGate, nearly all coverage was critical of gaming and gaming journalism, with discourse noting the misogyny of gamers and cyberbullying through gaming. Following GamerGate, coverage reflected a return to the mix of the dystopian and utopian frames Williams (2003) identified, with ongoing discussions of ethics in gaming journalism - even years after the controversy reached its head-as well as discussion of gaming's pro-social benefits.

Yet, even with the emphasis on utopian framing prior to the controversy, a pattern clearly emerged: the quality of gaming journalism was poor, a common sentiment about gaming journalism (see Nieborg and Sihvonen, 2009). Kunkel's work was lauded because it was exceptional in comparison to the rest of gaming journalism, while Parkin's was derided for appearing to be an exemplar of gaming journalism. So, while journalistic discourse broadly noted the value of covering gaming in terms of its economic impact, artistic contributions, discussions of gender, and its continued role in discussions of violence, journalists did not indicate that gaming journalists did it well.

\section{Paradigmatic values}

RQ2 posed: How does the metajournalistic discourse about gaming journalism engage paradigmatic values of traditional journalism? GamerGate marked a time when traditional journalists were forced - by nature of the visibility of events - to contend with the paradigmatic challenge presented by the practices of gaming journalism. That said, thematically, the coverage studied throughout the sample - both before, during, and after GamerGate - remained relatively uniform in its marginalization of gaming journalism as not "pure" or "true" journalism.

This is already obvious in the discourse highlighted above. It is also indicated in the ways traditional journalistic discourse raised questions about gaming journalists' news work and independence.

A Tuscaloosa News columnist, who previously worked for the gaming website GameFront, noted: "I am led to believe that true journalism is not a priority at most game publications" (Owen, 2014). Based on his experiences in the field, the columnist noted 
several problems in gaming journalism. In describing the profits made by the hit Marvel Studios movie "The Avengers," the author noted that it was public knowledge how much the movie cost and how much revenue it made (Owen, 2014). In the gaming industry, publishers are under no obligation to provide sales numbers and there are no third parties to fill in the gaps. This is a problem in gaming journalism because "the journalists can't provide any perspective when a game studio is shut down by its overlords" (Owen, 2014). The reason for the lack of perspective is not just because gaming journalists are not provided the data, but also because they have not asked for it. The columnist implied that gaming journalists could consider granting anonymity - a practice fraught with concern in traditional journalism - in order to obtain budget numbers, but noted that information from anonymous sources does not tend to be used in gaming journalism. This concern indicates that hard news values have been used as a standard for judging gaming journalism - values that arts journalists have historically had trouble addressing (see Harries and Wahl-Jorgensen, 2007).

The discourse also questioned the journalistic independence of gaming journalists. Much of the discourse questioned the "close relationship between games journalists and games publishers" (Stuart, 2017). Journalists questioned whether gaming journalists can show "impartiality" when gaming journalists "rely heavily on working relationships with publishers" (Stuart, 2017). During the GamerGate controversy, gaming journalists were critiqued for allowing the movement to gather "legitimacy" simply because of their too-close relationship with the gaming industry (Camron, 2014). Gaming journalists were perceived as "little better than PR shills, trading favorable features and reviews for exclusive access to new titles or juicy freebies" (Stuart, 2017). Yet journalists acknowledge that working in partnership with the industry is to some degree inevitable in the "digital era" (Stuart, 2017).

The discourse indicted gaming journalists with working on behalf of game publishers and gaming journalism, and hence not meeting the "standards of quality" expected in traditional journalism (Stuart, 2017). In short, the "lack of legitimate critical voices" in gaming journalism created a vacuum in which "anonymous entities can do harm to both individuals and the medium as a whole" (see Foxman and Nieborg, 2016: 39). Furthermore, by offering a definition of journalism, this discourse is conducting the "definition making and boundary work" expected in metajournalistic discourse to, in this case, delegitimize gaming journalism (see Carlson, 2015: 360).

Metajournalistic discourse about gaming journalism questioned the commitment of gaming journalists to key values within traditional journalism. Unlike traditional journalism, gaming journalism failed to analyze and interpret its subject of study, it failed to adequately critique problems, and it lacked the independence to offer impartial coverage (see Fürsich, 2012). Gaming journalism failed to do the work, possess the resources, or use the tools of traditional journalism: it lacked the gravity to answer deep questions, lacked the savviness to extract industry data or use anonymous sources, and even lacked the sense to use a diverse mix of sources. Gaming journalists, at their worst, were indistinguishable from PR shills (Gwaltney, 2014). These are charges commonly leveled at cultural journalists in that the "close intertwinement of the culture industries and the press often leads to cultural journalists being accused of running errands for the culture industries" (Kristensen, 2018: 2170). Seen through the lens of Kristensen's (2018) discussion 
of "churnalism," the practices of gaming journalism would seem to have created an "inverted gatekeeping" situation in which too much power has been granted to the cultural industry (p. 2182).

Traditional journalistic values were put forward as the route to legitimacy. Gaming journalists, in comparison, were dangerously close to illegitimacy. This difference in values, then, had implications for the discursive placement of gaming journalism within the broader journalism ecosystem.

\section{Fitting in the ecology}

Finally, RQ3, asked: How does the metajournalistic discourse about gaming journalism place gaming journalism within the broader ecology of journalism? Two different discursive constructions were presented in metajournalistic discourse: an insider-outsider discourse that placed gaming journalism outside the bounds of legitimate journalistic practice, largely due to a market orientation, and a higher-lower discourse that placed gaming journalism beneath traditional journalism as a result of its low analytical quality.

The market orientation of gaming journalism was often referred to through critiques of journalists' independence (noted above). Gaming journalism was critiqued for focusing so heavily on "access to preview and review material" that tends to be tightly controlled by the industry (Stuart, 2017). As such, gaming journalists do not tend to be critical of the industry, since they depend on the industry to provide news about upcoming games. This market orientation is not unusual in lifestyle journalism, yet it represents a key difference that affects its place within the journalistic environment (see Hanitzsch, 2007).

Yet, during the GamerGate controversy, it is worth noting that game players did accuse gaming journalism of "collusion among developers and journalists" (Suellentrop, 2014), but simultaneously gaming journalists were attacked for their criticism of the gaming industry on the social issues most likely to be of public interest. Even when gaming journalists attempted to embrace a public service form of journalism during the GamerGate controversy, traditional journalists pointed out that gaming journalism's market orientation just led to the whole effort backfiring. Audiences got the best of the gaming journalists - the gamer identity cultivated over years of exclusionary journalistic strategy ended up leaving gaming journalists powerless during GamerGate to call for a "more diverse understanding of the gamer identity" (see Foxman and Nieborg, 2016: 14). By noting the reader response to gaming journalism, traditional journalistic discourse engaged in standard metajournalistic discourse by deconstructing negative responses to that journalism (see De Maeyer and Holton, 2016). The metajournalistic discourse also acknowledged that gaming journalism's place in the field is constructed by journalistic actors as well as actors outside of journalism (see Carlson, 2015). Throughout the discourse, gaming journalism, then, is located as an "outsider" type of journalism, even while the topics covered were clearly delineated as newsworthy for insiders in the broader journalistic ecology.

Gaming journalism was also constructed as operating on a lower level in comparison to traditional journalism. In fact, gaming reviews did not even measure up to movie 
reviews (a form of lifestyle journalism), putting gaming journalism at least two rungs below traditional journalism. Journalists argued that gaming reviewers should be "interested in the meaning of games" as opposed to focusing exclusively on "whether or not the game is any good" (Watson, 2016). Yet, journalists acknowledged that this level of criticism can be difficult given that the "job is really hard" when gaming journalists are expected to work through the "torment of playing 100-plus games in a year" (Owen, 2014). The time expectations and workload are implied to be part of the reason gaming journalists may lean on relationships built with game publishers. Yet in the speed of their work, they are likely to miss the "narrative complexity and aesthetics" in many of today's games (McGinn, 2010). Hence, many journalists saw "intelligent video game criticism" as an unlikely outcome (McGinn, 2010), thereby, jeopardizing their role as a venue for cultural negotiations (see Fürsich, 2012) and their role as a vehicle for collective memory on the gaming imaginary (see Kirkpatrick, 2013).

Here the work conducted in gaming journalism is perceived to be under the same damning pressure experienced throughout the journalistic field, but that, perhaps, gaming journalism did not handle it with the professionalism of traditional journalism. As such, the analysis offered by gaming journalism is presented as ill-befitting the content being analyzed. This assessment operates under some level of assumption that, in traditional journalism, hard news topics like politics and business are granted thorough, nuanced analysis that is seen as lacking in gaming journalism. Simultaneously, the discourse grants "hard news" topics a higher rung on the journalistic ladder than "soft news" (see Hanusch, 2012).

Furthermore, the findings here reflect what Williams (2003) described as the negative framing of gaming - that it often happens through reflection of political rhetoric. This negative framing shaped the coverage, not just of games, but also of gaming journalism. And it is worth noting that these findings do not appear to be wholly at odds with how gaming journalists critique their own work-gaming journalists "do seem aware of the compromised identity and space they occupy" (see Foxman and Nieborg, 2016: 20). Gaming journalists, like cultural journalists, generally tend toward apathy in conceptualizing their own profession (see Jaakkola, 2015) and tend to focus on their specialized knowledge as opposed to adherence to professional standardsorientations that would naturally affect how gaming journalists are placed within the journalistic ecology.

\section{Conclusion}

Journalistic discourse recognized the suitability of the gaming world as an important topic to report. The topic alone did not mark gaming journalism as an inferior species in the journalism ecology. However, the journalists saw the topic as relevant only in as much as it overlapped with other hard news topics. When the journalistic discourse focused on game reviewing, implicit judgments emerged. Entertainment, as a topic, was about giving audiences what they wanted. The topic, in other words, was discursively tied to market-driven, rather than public service-driven, journalism. Thus, even at the level of a news topic, lifestyle journalism is ultimately still seen as a less legitimate form of journalism (Hanusch, 2012). 
The GamerGate controversy in 2014 caused a spike in the coverage represented in this sample. Nearly half of the sample, 27 articles, responded explicitly to the events of GamerGate. So the controversy — as illustrated by Perreault and Vos (2018) - seemingly forced journalists to acknowledge gaming journalism. Throughout the period covered, gaming journalism was seen as a flawed and inferior form of journalism. But gaming journalists came through the GamerGate controversy and declared that they had professionalized, leaving behind their roots in enthusiast journalism, particularly having just tackled important issues honestly and fearlessly (Perreault and Vos, 2018). The journalistic discourse did not give gaming journalism quite so much credit. Gaming journalism's past continued to be raised following the controversy and contemporary missteps were seized upon. This was classic boundary work (Carlson and Lewis, 2015), discursively pushing gaming journalism to the fringes of the journalism ecology. Gaming journalism was deemed to be operating on a surface level and cultivating an audience engaging in inappropriate practices - hence, gaming journalism itself was deemed inappropriate (Carlson, 2015). Furthermore, gaming journalists" "lack of faith" in their own field (Foxman and Nieborg, 2016: 8) and their ambivalence regarding their own societal contributions (Harries and Wahl-Jorgensen, 2007) resulted in a mirrored ambivalence by traditional journalists. If gaming journalists articulated uncertainty regarding their societal contributions, traditional journalists articulated even less certainty. Gaming journalism seemed to be operating outside the bounds of legitimate journalistic practice through its churnalism, and hence, traditional journalism could not expect the societal contributions one would expect from appropriate journalistic practice (Eldridge, 2019).

Gaming journalism was portrayed as lacking professionalism, still consigned to a lower and marginal form of journalism. Traditional journalists based this hierarchy on differences in paradigmatic professional values and journalistic savviness. The newcomers remained trapped in their status of being late to the game. Even when the journalistic discourse acknowledged that gaming journalists faced time pressures that were becoming increasingly common throughout the journalism ecology, traditional journalists separated themselves based on their professionalism and hence their superior ability to deal with those pressures. In terms of gaming journalism's place within the journalism ecology, gaming journalism seemingly found itself on the fringes when it came to topic orientation, audience orientation, style orientation, orientation by voice, and likely in terms of orientation by political engagement and professional status. However, only some of these considerations explicitly made it into the metajournalistic discourse.

The study's conclusions are perhaps limited by the fact that the body of discourse about gaming journalism was not large. This was offset, however, by the consistency of traditional journalism's critique, even consistency from those traditional journalists who once wrote for the gaming press. Indeed, the dearth of articles - even in the face of the GamerGate controversy - is perhaps its own statement about the field's relative indifference to gaming journalism. While the study is largely limited to US discourse, it should be noted that the findings do comport with, and provide empirical substance to, the lifestyle and cultural journalism literature that is predominantly from outside the United States. More work remains to be done on the broader matter of mapping the journalistic ecology. Metajournalistic discourse is clearly a site where this mapping work is being 
done (Carlson, 2015). More analysis of the many types of journalism, and where these types fit into the ecology and on what terms, is still needed.

\section{Funding}

The author(s) disclosed receipt of the following financial support for the research, authorship, and/ or publication of this article: This project is funded by the Donald W. Reynolds Journalism Institute.

\section{Note}

1. Deuze (2005) suggests a shared occupational journalistic ideology that values an "ideal-typical" journalist committed to "working truthfully," "operating as a watchdog," "enabling citizens to be self-governing," but is also "one-dimensional and sometimes nostalgic for perhaps the wrong reasons" (p. 458). Nevertheless, he argues, journalists routinely articulate binary oppositions such as those between traditional journalism and lifestyle journalism in such a manner as to favor traditional journalism.

\section{ORCID iD}

Gregory Perreault (iD https://orcid.org/0000-0002-6645-1117

\section{References}

Alba-Juez L (2009) Perspectives on Discourse Analysis: Theory and Practice. Newcastle upon Tyne: Cambridge Scholars.

Allan S and Thorsen E (2009) Citizen Journalism: Global Perspectives. New York: Peter Lang.

Berkowitz D (2000) Doing double duty: paradigm repair and the Princess Diana what-a-story. Journalism 1(2): 125-143.

Bruns A, Wilson J and Saunders B (2009) Reporting the 2007 Australian federal election. In: Allan S and Thorsen E (eds) Citizen Journalism: Global Perspectives. New York: Peter Lang, pp. 197-208.

Camron M (2014) Rocky mountain gamer: it's all fun and (video) games - until someone gets hurt. The Daily Camera, 9 October. Available at: https://www.dailycamera.com/2014/10/09/ rocky-mountain-gamer-its-all-fun-and-video-games-until-someone-gets-hurt/

Candlin CN (1997) General editor's preface. In: Gunnarsson B-L, Linell P and Nordberg B (eds) The Construction of Professional Discourse. London, New York: Routledge, pp. viii-xiv.

Carlson M (2009) The reality of a fake image: news norms, photojournalistic craft, and Brian Walski's fabricated photograph. Journalism Practice 3(2): 125-139.

Carlson M (2014) Gone, but not forgotten: memories of journalistic deviance as metajournalistic discourse. Journalism Studies 15(1): 33-47.

Carlson M (2015) Metajournalistic discourse and the meanings of journalism: definitional control, boundary work, and legitimation. Communication Theory 26(4): 349-368.

Carlson M and Lewis SC (eds) (2015) Boundaries of Journalism: Professionalism, Practices and Participation. London and New York: Routledge.

Carlson M and Usher N (2016) News startups as agents of innovation: for-profit digital news startup manifestos as metajournalistic discourse. Digital Journalism 4(5): 563-581.

Carvalho A (2008) Media(ted) discourse and society. Journalism Studies 9(2): 161-177.

Clarke D (2014) Gamers misogynistic? Some certainly are. Irish Times, 18 October. Available at: https://www.irishtimes.com/culture/games/game-reviews/are-gamers-misogynistic-somecertainly-are-1.1968159 
Chong P (2019) Valuing subjectivity in journalism: bias, emotions, and self-interest as tools in arts reporting. Journalism 20(3): 427-443.

Coffey A and Atkinson P (1996) Making Sense of Qualitative Data: Complementary Research Strategies. Thousand Oaks, CA: SAGE.

Coward R (2013) Speaking Personally: The Rise of Subjective and Confessional Journalism. New York: Macmillan International Higher Education.

De Maeyer J and Holton AE (2016) Why linking matters: a metajournalistic discourse analysis. Journalism 17(6): 776-794.

Deuze M (2005) What is journalism? Professional identity and ideology of journalists reconsidered. Journalism 6(4): 442-464.

Dovey J (2008) Dinosaurs and butterflies-media practice research in new media ecologies. Journal of Media Practice 9(3): 243-256.

Eldridge SA (2019) "Thank god for Deadspin": interlopers, metajournalistic commentary, and fake news through the lens of "journalistic realization." New Media \& Society 21: $856-878$.

Ellis J (2012) Game on: how polygon wants to rethink video game journalism. NiemanLab, 31 October. Available at: https://www.niemanlab.org/2012/10/game-on-how-polygon-wants-torethink-video-game-journalism/

Emerson RM, Fretz RI and Shaw LL (2011) Writing Ethnographic Fieldnotes. Chicago, IL: University of Chicago Press.

Ferrucci P and Vos TP (2017) Who's in, who's out? Digital Journalism 5(7): 868-883.

Flaxman S, Goel S and Rao JM (2016) Filter bubbles, echo chambers, and online news consumption. Public Opinion Quarterly 80(1): 298-320.

Foxman MH and Nieborg DB (2016) Between a rock and a hard place: games coverage and its network of ambivalences. Journal of Games Criticism 3: 1-26.

Fram SM (2013) The constant comparative analysis method outside of grounded theory. The Qualitative Report 18(1): 1-25.

From U (2010) The reading of cultural and lifestyle journalism. Northern Lights: Film \& Media Studies Yearbook 8(1): 157-175.

Fürsich E (2012) Lifestyle journalism as popular journalism: strategies for evaluating its public role. Journalism Practice 6(1): 12-25.

Glaser BG and Strauss AL (1968) The Discovery of Grounded Theory: Strategies for Qualitative Research. London: Weidenfeld and Nicolson.

Gwaltney J (2014) Some thoughts on the tiny world of video game journalism. 11 March. Available at: http://antagonizethehorn.com/2014/03/11/somethoughts-on-the-tiny-world-ofvideo-gamejournalism/

Hall S (1980) Culture, Media, Language: Working Papers in Cultural Studies: 1972-79. London: Hutchinson.

Hanitzsch T (2007) Deconstructing journalism culture: toward a universal theory. Communication Theory 17(4): 367-385.

Hanusch F (2012) Broadening the focus: the case for lifestyle journalism as a field of scholarly inquiry. Journalism Practice 6(1): 2-11.

Harries G and Wahl-Jorgensen K (2007) The culture of arts journalists: elitists, saviors or manic depressives? Journalism 8(6): 619-639.

Heikkilä R, Lauronen T and Purhonen S (2018) The crisis of cultural journalism revisited: the space and place of culture in quality European newspapers from 1960 to 2010. European Journal of Cultural Studies 21(6): 669-686.

Hindman EB (2005) Jayson Blair, The New York Times, and Paradigm Repair. Journal of Communication 55(2): 225-241. 
Hum N (2013) A new era of video game journalism: gaming shows and websites close as grassroots approach takes over. Here, 14 March. Saint John, Fredericton and Moncton edition.

Ingle B (2013) BOB INGLE: video games a distraction for the NRA. Courier Post, 26 April. Available at: https://login.proxy006.nclive.org/login?url=https://search.proquest.com/docview/1346348663? accountid $=8337$

Jaakkola M (2015) The Contested Autonomy of Arts and Journalism: Change and Continuity in the Dual Professionalism of Cultural Journalism. Tampere: Tampere University Press.

Jeffries LB (2009) The new games journalism. Popmatters, 17 June. Available at: https://www. popmatters.com/73112-the-new-game-journalism-2496025739.html

Johnson N (2010) The history of video game journalism. Cheat Code Central. Available at: https:// www.cheatcc.com/extra/videogamejournalismhistory2.html

KainE(2014) The catch 22 of video game journalism. Forbes, 13 November. Available at: https://www. forbes.com/sites/erikkain/2014/11/13/the-catch-22-of-video-game-journalism/\#4084ad385301

Kirkpatrick G (2013) Computer Games and the Social Imaginary. Cambridge: Polity.

Kristensen NN (2018) Churnalism, cultural (inter)mediation and sourcing in cultural journalism. Journalism Studies 19(14): 2168-2186.

Leech NL and Onwuegbuzie AJ (2008) Qualitative data analysis: a compendium of techniques and a framework for selection for school psychology research and beyond. School Psychology Quarterly 23(4): 587.

McGinn D (2010) What's not to criticize? The Globe and Mail, 26 June, R.12.

Massanari A (2017) \# Gamergate and the fappening: how Reddit's algorithm, governance, and culture support toxic technocultures. New Media \& Society 19(3): 329-346.

Mullainathan S and Shleifer A (2005) The market for news. American Economic Review 95(4): 1031-1053.

Newman MZ and Levine E (2012) Legitimating Television: Media Convergence and Cultural Status. New York: Routledge.

Nieborg DB and Sihvonen T (2009) The new gatekeepers: the occupational ideology of game journalism. In: Proceedings of the 2009 DiGRA international conference: breaking new ground: innovation in games, play, practice and theory, London, 1-4 September.

Owen P (2014) Game bytes: video game journalism needs to dig deeper. The Tuscaloosa News, 18 May. Available at: https://login.proxy006.nclive.org/login?url=https://search.proquest.com/ docview/1014166316? accountid $=8337$

Pavlik JV (2013) Innovation and the future of journalism. Digital Journalism 1(2): 181-193.

Perreault G and Stanfield K (2019) Mobile journalism as lifestyle journalism? Field theory in the integration of mobile in the newsroom and mobile journalist role conception. Journalism Practice 13: 331-348.

Perreault GP and Vos TP (2018) The GamerGate controversy and journalistic paradigm maintenance. Journalism 19(4): 553-569.

Prebble L (2014) Playtime: the gaming column: telling the story to a whole new audience. Poughkeepsie Journal, 9 February, p. 33.

Riegert K, Roosvall A and Widholm A (2015) The political in cultural journalism: fragmented interpretative communities in the digital age. Journalism Practice 9(6): 773-790.

Sauter M (2016) A game room of one's own: Simon Parkin's Death by Video Game is elegant, but misses half the audience. The Financial Post, 25 June. Available at: https://www.pressreader. com/canada/national-post-latest-edition/20160625/282634621919693

Scolari CA (2012) Media ecology: exploring the metaphor to expand the theory. Communication Theory 22(2): 204-225.

Shenzhen Daily (2014) Anita Sarkeesian takes on misogynist hate group GamerGate. Shenzhen Daily, 11 November. Available at: http://www.szdaily.com/content/2014-10/24/content_10578276.htm 
Slotnik DE (2011) Bill Kunkel: July 21, 1950-Sept. 4, 2011 -a creator of video game journalism. Pittsburgh Post-Gazette, 19 September, B. 3.

Sparre K and From U (2017) Journalists as tastemakers: an analysis of the coverage of the TV series Borgen in a British, Swedish and Danish newsbrand. In: Kristensen NN and Riegert K (eds) Cultural Journalism in the Nordic Countries. Gothenburg: Nordicom, pp. $159-178$.

Stuart K (2017) Game changers: how the increasing cultural significance of video games is reflected in our coverage. The Guardian, 21 July. Available at: https://www.theguardian. $\mathrm{com} / \mathrm{membership} / 2017 / \mathrm{jul} / 21 /$ game-changers-how-the-increasing-cultural-significance-ofvideo-games-is-reflected-in-our-coverage

Suellentrop C (2014) Can video games survive? The New York Times, 26 October. Available at: https://www.nytimes.com/2014/10/26/opinion/sunday/the-disheartening-gamergate-campaign.html

Tracy CM (2012) The Newsphere: Understanding the News and Information Environment. New York: Peter Lang International Academic Publishers.

Trueman D (2013) Video games level up to become modern art. The Financial Post, 15 March.

Tsukayama H (2014) Trade group responds to "Gamergate.." The Washington Post, 16 October.

Van Dijk TA (1980) Text and Context: Explorations in the Semantics and Pragmatics of Discourse. London: Longman.

Vos TP, Craft S and Ashley S (2012) New media, old criticism: bloggers' press criticism and the journalistic field. Journalism 13(7): 850-868.

Watson S (2016) Toward a constructive technology criticism. Columbia Journalism Review, 4 October.

Williams D (2003) The video game lightning rod. Information Communication \& Society 6(4): 523-550.

Winch SP (1997) Mapping the Cultural Space of Journalism: How Journalists Distinguish News from Entertainment. Westport, CT: Praeger Publishers.

Wos J (2014) Girls allowed. Pittsburgh Tribune Review, 22 December. Available at: https://login. proxy006.nclive.org/login?url=https://search.proquest.com/docview/1638759739?accoun tid $=8337$

\section{Author biographies}

Gregory Perreault is an assistant professor of Multimedia Journalism at Appalachian State University. He researches media sociology, lifestyle journalism, media representations, and emerging media. His research has been widely discussed in publications including VICE, Le Monde, Kotaku, and Yahoo! Games.

Tim Vos is professor and director of the School of Journalism at Michigan State University. He is co-author, co-editor, or editor of four books and the International Encyclopedia of Journalism Studies. He researches roles of journalism, media sociology and gatekeeping, media history, and media policy. 